\title{
Aspects concerning the circularity and cylindricity deviation of a work piece processed by turning
}

\author{
Mihai Boca ${ }^{1, *}$, Gheorghe Nagit $^{1}$, and Florentin Cioată ${ }^{2}$ \\ ${ }^{1}$ Machine Manufacturing Department, Machine Manufacturing and Industrial Management Faculty, \\ Gheorghe Asachi Technical University, D. Mangeron Blvd, No. 59A, Iaşi, România \\ ${ }^{2}$ Machine Tools and Production Systems Department, Machine Manufacturing and Industrial \\ Management Faculty, Gheorghe Asachi Technical University, D. Mangeron Blvd, No. 59A, Iaşi, \\ România
}

\begin{abstract}
All the cutting processes impose certain specifications for the work pieces obtained. In such conditions, the parameters as tolerance, roughness and geometrical deviations must be well known in order to determine the obtained accuracy of the processed work pieces. During the cutting process, due to some influences from the MTDW (Machine Tool, Device Work piece), a work piece can result with processing errors. In order to compensate this errors or, if it is possible to eliminate them, some measurement of the work piece dimensions are taken. In this way, the present study propose an evaluation of such aspects in order to establish, based on the work piece shape on radial and longitudinal direction, the imposed measures to compensate the processing errors. For high accuracy of the obtained data, an automated device will be used. The results will highlight the influenced areas of the processed work pieces and the possible factors which conduct to generating errors.
\end{abstract}

\section{Introduction}

In most cutting processes the obtained accuracy of the manufactured parts depends on influences exerted, during the processing, by several factors as cutting parameters, cutting force, work piece stiffness, machine-tool behaviour and others. Not in all cases the accuracy expected is similar with the predicted one. From the cutting processes, the turning process is one of most used processes in industry and implies a high level of work piece accuracy. From this reason, it is mandatory to find the entire error sources that can modify the expectations concerning the obtained accuracy of the manufactured work pieces.

During the cutting processing, due to some unexpected influences produced in the inside of the MTDW system (Machine, Tool, Device, Work piece), the accuracy might suffer some changes. Concerning the work piece shape obtained into a turning process, excluding the roughness parameter, the errors which occur can be associated to the radial deviations measured in transversal sections of the work piece and on the work piece profile

\footnotetext{
*Corresponding author: mihaitzaboca@yahoo.com
} 
generator along the work piece length. Depending on the differences between the expected profile and real one, the differences should be included into the tolerances prescripts. In such conditions, a well knowing of the real work piece profile and of the mentioned influences, both in radial and in longitudinal direction, it can improve the obtained accuracy of the manufactured products. From this reason the present paper wants to present several aspects concerning the measurement made on some work pieces processed into a turning process, in order to highlight the aspects mentioned earlier and to furnish some measures to avoid work piece errors.

\section{General considerations}

Usually, the accuracy of a work piece is expressed by his dimensional values, which contain the specification of tolerances. Beside the large dimensions of the work piece, the cylindricity deviation, both with the profile cilindricity represents the main aspects which furnish an idea about the wok piece accuracy. The cylindricity deviation appears in case of a cylindrical work piece processed by turning and it is caused by the cutting force variation during processing. This type of error consists by a non-uniform shape profile founded on entire work piece length. For measuring such kind of error it is necessary to measure the work piece shape in several transversal sections along the work piece length [1]. This method is known as the measuring method on radial direction, made in several sections perpendiculars to the work piece axis. Depending on the technique of the applied method, two ways of measurement can be distinguished: the measurement which is made with contact in points of the measured section and measurement which is made with continuous contact in measured section. In this way it is obtained the cylindricity deviation that includes the circularity error in each considered section perpendicular to the work piece axis and considers the values measured in all the sections disposed on the entire length of the work piece. Depending on the used device, the measurements can be taken by contact with work piece as in our case, or without contact when is used a laser device.

For the present study it was chosen the method of measuring with contact in points. Also, the work piece profiles can highlight the effective cylindrical shape of these, supposing that a number of measured sections can give an image of the profile shape of the work piece in axial sections. This fact is assumed by the hypothesis of concentricity of the real circular sections from each measured section with the longitudinal axis of the processed surface.

The studies made until now on this topic presents as errors sources the following factors: the work piece deflection, initial geometry of the raw part [1], vibration, thermal deformations, machine tool and tool wear [3] and others. In the last year a sustained activity was developed on errors compensation [2]. The first step to make an error compensation is to know the values of the errors appearance and the factors which conduct to their presence [1]. Beside these, the technical literature presents a series of studies related to MTDW stiffness, which can justify the cilindricity and cilindricity deviations. Between them, the study made by Olvera [2] presents some aspects concerning the evaluation of the MTDW components stiffness along his kinematic chain. He noted that a percentage of $21 \%$ of the errors are generated by the uncompensated thermal error, tool flexibility, material instability and axis acceleration, all these in case of classical cutting machines and CNC machines. Another study [3], using a FEM analysis, presents the deflection of the tool, due to the cutting force influences, as main parameter which can cause cylindricity deviations. Also, the Renjith author [3], purposes a Taguchi optimization plan for minimize the cutting tool deflection. Another approach concerning the cylindricity and cilindricity deviations presents an effective measurement of a rod, using a two points measurement, in order to reduce the errors caused by the spindle rotary movement [4]. 


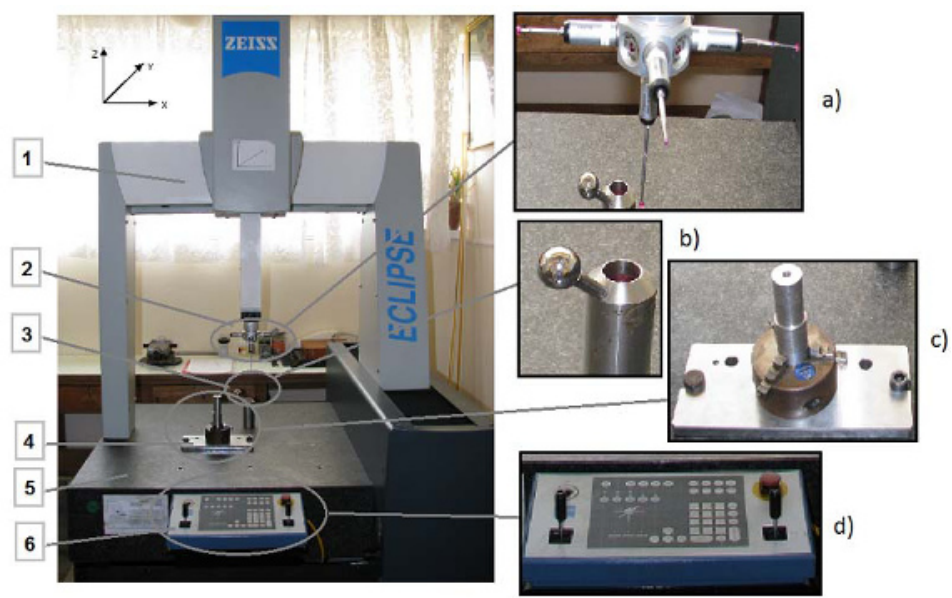

Fig. 1. Zeiss Eclipse Measurement Coordinate Machine: 1 - pillar machine, 2 - measurement head, 3 - calibration sphere, 4 - work piece clamping system; 5 - granite table; 6 - command panel.

\section{Experimental setup}

For the experimental study it was used a Zeiss Eclipse equipment presented in Figure 1,which allows to make measurements on three axes. The measurement head (Figure 2.a.) has possibility to use multiple spheres with diameters between 3 and $5 \mathrm{~mm}$. The head used in this study has a diameter of $3.97 \mathrm{~mm}$, dimension specified by the technical book of machine in case of the measured work pieces and which depends by the surface roughness obtained after processing. The clamping system chosen (Figure 2.) was represented by a classical tailstock in order to maintain the initial processing conditions. The measurement accuracy of the machine is $0.001 \mu \mathrm{m}$, reported to the displacement error of the machine axis table.

In order to determine the cilindricity error, both with cylindricity deviation, an experimental methodology was used. The experimental measurement procedure uses the coordinate measurement system of the measurement equipment and consists into a couple of measurement made on several radial sections of the work piece, together with measurement of the work piece profile along his length. The experimental method applied for measuring the diameter of the cylindrical surface it is an absolute method which supposed to evaluate directly the sectors chosen for reconstructed the real shape of the processed work piece. Due to the necessity of knowing the dimensional variations of the processed surface, reported to the measured work piece length, the work piece diameter it

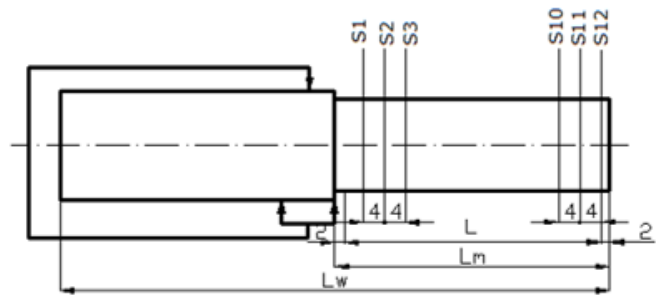

a)

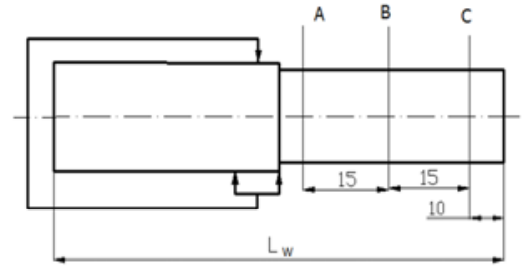

b)

Fig. 2. The measuring strategy for determine the work piece diameter, along the work piece axis and transverse to the work piece. 
Table 1. The measuring strategy for determining the workpiece diameter

\begin{tabular}{|c|c|c|c|c|c|c|c|c|}
\hline \multirow[t]{3}{*}{$\begin{array}{l}\text { Measured } \\
\text { section }\end{array}$} & \multicolumn{4}{|c|}{$\begin{array}{l}\text { Measured nominal diameter values d } \\
{[\mathrm{mm}]}\end{array}$} & \multicolumn{4}{|c|}{ Cilindricity error $[\mathrm{mm}]$} \\
\hline & \multicolumn{4}{|c|}{ Work piece number } & \multicolumn{4}{|c|}{ Work piece code } \\
\hline & 1 & 2 & 3 & 4 & 1 & 2 & 3 & 4 \\
\hline $0(\mathrm{SI})$ & 15.743 & 25.0298 & 14.6019 & 25.4704 & 0.0803 & 0.0989 & 0.0728 & 0.0633 \\
\hline 4 (SII) & 15.2739 & 25.0424 & 14.9434 & 25.4684 & 0.0835 & 0.0939 & 0.063 & 0.0731 \\
\hline 8 (SIII) & 15.3422 & 25.0512 & 14.9702 & 25.4732 & 0.0824 & 0.0715 & 0.0948 & 0.0743 \\
\hline 12 (SIV) & 15.2379 & 25.0487 & 14.9472 & 25.4711 & 0.069 & 0.0673 & 0.0731 & 0.0746 \\
\hline $16(\mathrm{SV})$ & 15.2249 & 25.0561 & 14.9763 & 25.4769 & 0.0676 & 0.0622 & 0.065 & 0.0819 \\
\hline 20 (SVI) & 15.2191 & 25.0569 & 14.9735 & 25.4765 & 0.0712 & 0.0554 & 0.0625 & 0.078 \\
\hline 24 (SVII) & 15.2934 & 25.059 & 14.9092 & 25.4785 & 0.0762 & 0.0483 & 0.0702 & 0.0767 \\
\hline 28 (SVIII) & 15.2961 & 25.0353 & 14.8923 & 25.4736 & 0.0744 & 0.0479 & 0.0817 & 0.0796 \\
\hline 32 (SIX) & 15.2974 & 25.0278 & 14.93 & 25.4776 & 0.0704 & 0.0409 & 0.0499 & 0.0717 \\
\hline $36(\mathrm{SX})$ & 15.3912 & 25.0398 & 14.9461 & 25.4756 & 0.0779 & 0.0367 & 0.0611 & 0.0763 \\
\hline 40 (SXI) & 15.3898 & 25.0324 & 14.9462 & 25.4765 & 0.077 & 0.0459 & 0.0736 & 0.0729 \\
\hline 44 (SXII) & 15.4054 & 25.0612 & 14.8314 & 25.4785 & 0.0672 & 0.0371 & 0.0777 & 0.0653 \\
\hline 48 (SXIII) & & & 14.7999 & 25.4788 & & & 0.0659 & 0.0762 \\
\hline 52 (SXIV) & & & 14.813 & 25.4774 & & & 0.089 & 0.0702 \\
\hline $56(\mathrm{SXV})$ & & & 14.9022 & 25.4798 & & & 0.0893 & 0.00710 \\
\hline
\end{tabular}

will be measure in several sections perpendicular on the work piece axis. More precisely, it was measured eight work piece, but only four of them were chosen as presenting the significant results to be discussed, other work pieces do not show relevant information. In this way each section was placed on a distance established at $4 \mathrm{~mm}$ one from another, in order to offer complete measurement informations concerning the work piece shape. The first and the last measurement sections were placed at $2 \mathrm{~mm}$ distance between the measuring limits of the end / beginning of the work piece (Figure 2b). In the same figure it was presented the strategy to determine the cilindricity error, measuring the work piece in four positions. In this way it was measured 12 sectors on the short wok pieces and 15 sectors on long wok pieces. This fact is considered as reason for eliminating the possible errors which could be inserted into the measurement results, possible dimensional or shape errors, which regularly are founded to the reference end lengths. With the symbol $\mathrm{L}_{\mathrm{w}}$ was noted the work piece length, with $\mathrm{L}_{\mathrm{m}}$ the theoretical, respectively with $\mathrm{L}$ the effective measurement length. The orientation, positioning and clamping of the measured work piece it was succeeded using the clamping system of the measurement device used. The measured diameters which characterize the cylindrical surface of the work piece processed allow determining directly the variation of the dimensional characteristic of the processed surface.

A steel alloy $41 \mathrm{Cr} 4$ it was used for the processing work pieces. The sample dimensions have two values: $18 \times 100 \mathrm{~mm}$ and $25 \times 125 \mathrm{~mm}$. It is considered that the used material is homogeneous and isotropic, to assure a uniform deformation of the work piece material during processing. As cutting parameters was chosen depth of cut $a_{p}=1.5 \mathrm{~mm}$, speed $\mathrm{s}=35.83 \mathrm{~m} / \mathrm{s}$ and feed $\mathrm{f}=0.023 \mathrm{~mm} /$ rot. The presented values was obtained considering a research experiment planning furnish by a Anova simulation, made in Datafit software, taking into account two values for each parameter of interest $\left(a_{p}=1.5\right.$ and $2.5 \mathrm{~mm}$, work piece diameter $\mathrm{D}=18$ and $30 \mathrm{~mm}$ and work piece length $\mathrm{L}_{\mathrm{W}}=100$ and $125 \mathrm{~mm}$, with $\mathrm{L}=48$ $\mathrm{mm}$ measured length, respectively $\mathrm{L}=60 \mathrm{~mm}$, and $\mathrm{L}_{\mathrm{m}}=48 \mathrm{~mm}$ and $61 \mathrm{~mm}$ ).

In the Table 1 are presented the values corresponding to the nominal measured diameter of the considered work pieces and the cilindricity errors for each measured sector (given by mean of measured values). The graphical results exposed in the Figure 3 presents four of the eight work pieces considered. It can be observed the cylindrical shape corresponding both to the short work pieces and for the biggest ones. In the Figure 4 are presented graphical representations of the cilindricity error corresponding to the work piece no. 3 , 


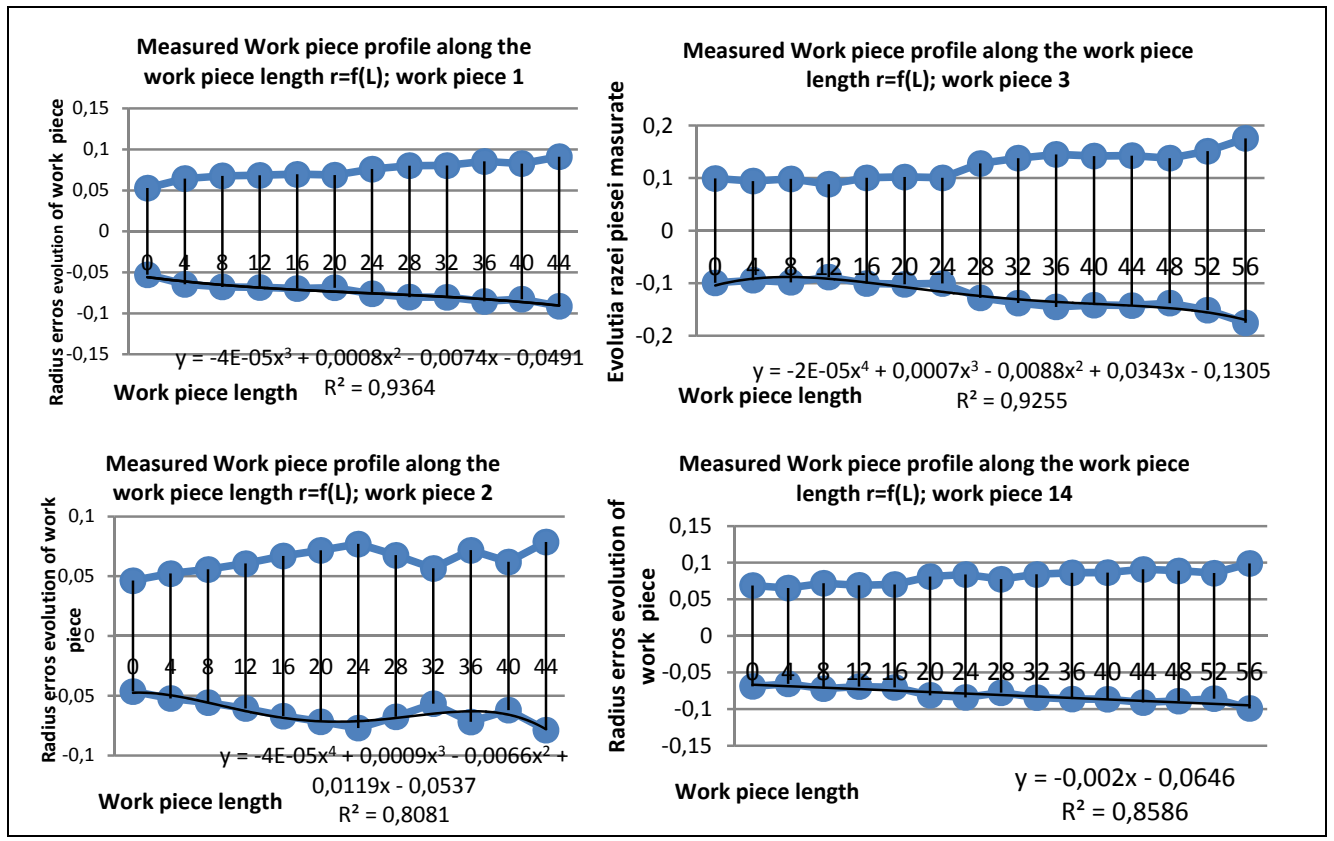

Fig. 3. Graphical representation of the cylindrical error of the most significant processed work pieces

assumed as the work piece with greater deviations justified by a weak stiffness of the work piece and greater cutting force in comparison with these. In this case, depending by the tolerances specified, the manufactured work pieces can be accepted or not for the following stages of research.

\section{Conclusions}

After processing all the work pieces concerning the cylindricity deviation, some observations can be highlighted:

- all parts dimensions of the work pieces processed by turning with feed, on sections perpendicular to the axis diameter, varies incrementally over tolerances prescript, starting at its clamped end into the tailstock to the free end of the processed part; this evolution of the diameter varies along the length of the processed surface, evolution materialized by a double concavity (customized by the funnel-shaped) of the work piece, normal evolution characteristic to the work pieces clamped at one end;

- it is observed a pronounced variation of the processed section diameter, this situation is highlighted in case of increased cutting length, both with maintaining a work piece constant diameter; it is noticed that of $25 \%$ cutting length increasing on the same depth of cut (from $100 \mathrm{~mm}$ to $125 \mathrm{~mm}$ ), the diameter of the processed work piece deviation increases almost with $10 \%$ (from $0.038 \mathrm{~mm}$ to $0.045 \mathrm{~mm}$ );

- the processing of the work pieces with a diameter of $18 \mathrm{~mm}$, on the same cutting length reveal that the diameter is changing between higher limits than in case of the work pieces with diameters of $28 \mathrm{~mm}$; also, at an increasing depth of cut (from $1.5 \mathrm{~mm}$ to $3 \mathrm{~mm}$ ) the difference between diameters becomes double (from $0.059 \mathrm{~mm}$ to $0.120 \mathrm{~mm}$ );

- once with $25 \%$ of length variation (from $100 \mathrm{~mm}$ to $125 \mathrm{~mm}$ ), for a constant depth of cut, it is noted that the variation of the processed diameter has a much quicker evolution than for the work piece with the diameter of $28 \mathrm{~mm}$; in this case, the limit becomes larger than 
$66 \%$ (from $0.059 \mathrm{~mm}$ to $0.090 \mathrm{~mm}$ ) to a $1.5 \mathrm{~mm}$ depth of cut and the same, with $60 \%$ (from $0.120 \mathrm{~mm}$ to $0.200 \mathrm{~mm}$ ) to $3 \mathrm{~mm}$ depth of cut; due to the high stiffness of the cross section

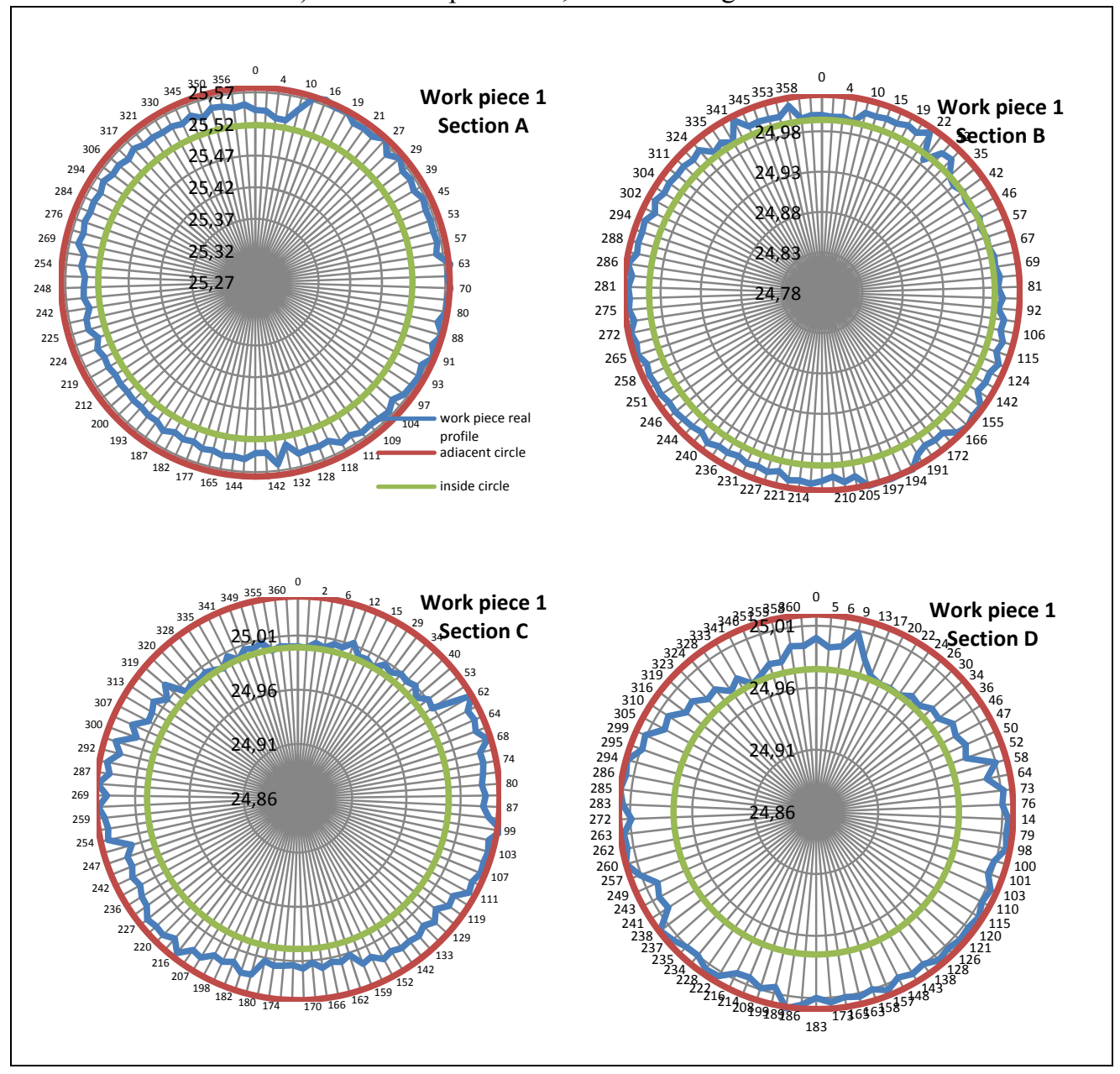

Fig. 4. Graphical representations of the diameter sections of the work piece no. 3 .

placed near of the work piece chuck, the error value is lower compared with the section located at the free end of the work piece which present a significant changing of the profile.

\section{References}

1. *** Kalsi Seals Handbook, D4 - Shaft deflection, runout, vibration, and axial motion, (Kalsi Engineering Inc. 2014)

2. D. Olvera, L. N. López de Lacalle, F. I. Compeán, Fz-Valdivielso, A. Lamikiz, F. J. Campa, Int J Adv Manuf Technol 60 (2012)

3. V. B. Renjith, M. Baby, K. R. Jayadevan, Int. J. of Scientific and Research Publications 3, 7, (2013)

4. Q. Chen, X. Tao, J. Lu, X. Wang, Hindawi Publishing Corporation Adv. in Materials Science and Engineering, 1 (2016) 